\title{
Spatio-Temporal Modelling of Noise Pollution
}

\section{Nur Nazmi Liyana Mohd Napi ${ }^{1}$, Mohd Hafizul Zainal ${ }^{1}$, Samsuri Abdullah ${ }^{1,2 *}$, Nazri Che Dom ${ }^{3}$, Amalina Abu Mansor ${ }^{4}$, Ali Najah Ahmed ${ }^{5}$, Marzuki Ismail ${ }^{2,4}$}

${ }^{1}$ Faculty of Ocean Engineering Technology and Informatics,

Universiti Malaysia Terengganu, 21030 Kuala Nerus, Terengganu, MALAYSIA

${ }^{2}$ Institute of Tropical Biodiversity and Sustainable Development,

Universiti Malaysia Terengganu, 21030 Kuala Nerus, Terengganu, MALAYSIA

${ }^{3}$ Centre of Environmental Health and Safety, Faculty of Health Sciences,

Universiti Teknologi MARA, 42300 Puncak Alam, Selangor, MALAYSIA

${ }^{4}$ Faculty of Science and Marine Environment,

Universiti Malaysia Terengganu, 21030 Kuala Nerus, Terengganu, MALAYSIA

${ }^{5}$ Institute of Energy Infrastructure, College of Engineering,

Universiti Tenaga Nasional (UNITEN), 43000 Kajang, Selangor, MALAYSIA

*Corresponding Author

DOI: https://doi.org/10.30880/ijie.2021.13.03.015

Received 20 December 2020; Accepted 01 May 2021; Available online 06 June 2021

\begin{abstract}
An undesired or hazardous outdoor sound produced by human activities is referred to as environmental noise. For example, the noise emitted through industrial activities and transportation networks such as road, rail and air traffic. In Malaysia, most of the schools located very close to the roadside and near busy places such as cities, shops, and residential areas. This study aims to analyze the environmental noise in terms of spatial and temporal analysis in two primary schools in Terengganu State. The noise monitoring had conducted in two (2) primary schools with different land use; residential area (Batu Rakit Primary School) and commercial area (Paya Bunga Primary School) on the school and non-school days by using Sound Level Meter (SLM). The spatial mapping had constructed by using SketchUp® 2018 and Surfer® version 11 software. The noise level between both study areas was significantly different based on a p-value of less than 0.05. It also surpassed the Department of Environment (DOE) of Malaysia's permitted limit, with the Equivalent Noise Level $\left(\mathrm{L}_{\text {Aeq }}\right)$ in residential areas being greater than in commercial areas due to traffic volume and noise from nearby activities. Lastly, the area near the roadside has higher critical noise pollution compared with the location that furthers from the roadside. In conclusion, this study is useful in creating awareness to the public about the noise pollution effect on primary school students and is also can be used for mitigation measures to have a better place for students to study.
\end{abstract}

Keywords: Noise pollution, residential, commercial, sound level meter, school, traffic volume

\section{Introduction}

Unwanted sound at high level is considered as environmental noise which might came from anthropogenic sources and has a long-term impact on people's health and the environment [1]. The engine and frictional contact between vehicle tyres, ground tyres, and the air produced noise from motor vehicles. At speeds more than $60 \mathrm{~km} / \mathrm{h}$, road contact 
noise typically outnumbers engine noise. The environmental noise pollution unit is the decibel (dB) is used to measure the sound power, sound intensity, and sound pressure level [2]. The flow rate of traffic, the vehicle's speed, the proportion of heavy vehicles, and the type of the road surfaces can all be used to calculate the sound pressure level emitted by traffic. Spatio-temporal refers to both space and time, with spatial denoting occupied space and temporal denoting time [3]. This study investigates environmental noise at primary schools through spatial and temporal analysis using sound level monitoring and noise mapping. In today's Malaysia, the majority of school buildings are placed in bustling areas such as cities, stores, and residential areas. This circumstance arises as a result of the scarcity of land on which to build a school or the rapid development that surrounds the schools. In Malaysia, several schools are located in busy areas that were erected many years before the evolution occurred, contributing to a significant level of noise pollution in the school environment. Noise problem nowadays was arising due to enlargement of economic, and modernization [4]. Noise can obstruct the teaching and learning process by interfering with educational activities [5]. High noise levels can have a direct impact on the learning process, especially for primary school students [6]. Besides, the spatial relationship of the road over the potential noise receptors needs to consider as it gives the noise impact to the human. Furthermore, critical points can be detected via noise mapping [7] as the exposure to noise is dominantly due to an increase in the number of motor vehicles on the road.

\section{Materials and Methods}

\subsection{Site Selection}

This study was conducted at two (2) primary schools. The monitoring sites were chosen based on the Local Plan of Kuala Nerus (RTKN) [8] and the Local Plan of Kuala Terengganu (RTKT) [9]. Batu Rakit Primary School was chosen as the site for the residential area (S1) and Paya Bunga Primary School for the commercial area (S2) as shown in Table 1 and Fig. 1.

Table 1 - Location of study areas

\begin{tabular}{|c|c|c|c|}
\hline Site & Location & Classification of Land Use & Coordinate of the study area \\
\hline $\mathrm{S} 1$ & Batu Rakit Primary School & Residential & $\begin{array}{l}\text { Latitude } 5^{\circ} 26^{\prime} 53.84 " \mathrm{~N}, \\
\text { Longitude } 103^{\circ} 2^{\prime} 44.74 " \mathrm{E}\end{array}$ \\
\hline $\mathrm{S} 2$ & Paya Bunga Primary School & Commercial & $\begin{array}{l}\text { Latitude } 5^{\circ} 19^{\prime} 53.78 " \mathrm{~N}, \\
\text { Longitude } 103^{\circ} 8^{\prime} 18.57 " \mathrm{E}\end{array}$ \\
\hline
\end{tabular}

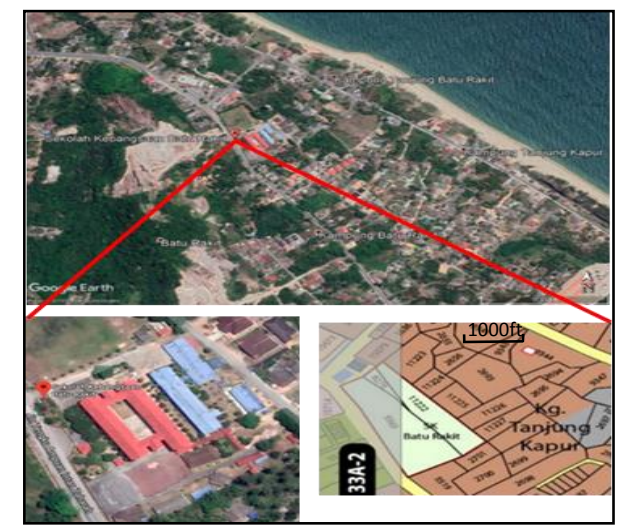

(a)

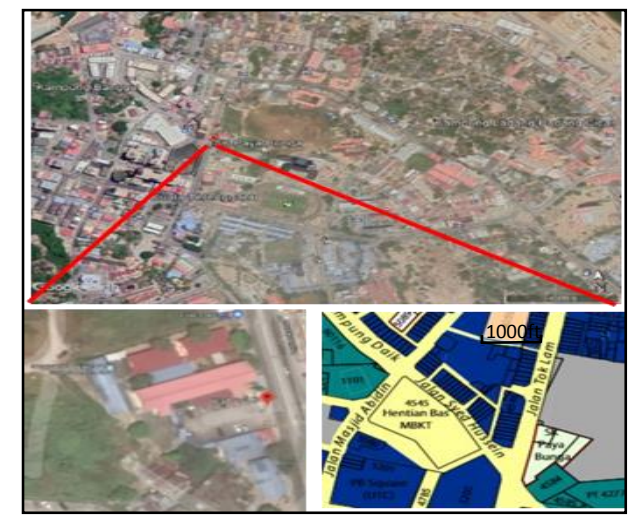

(b)

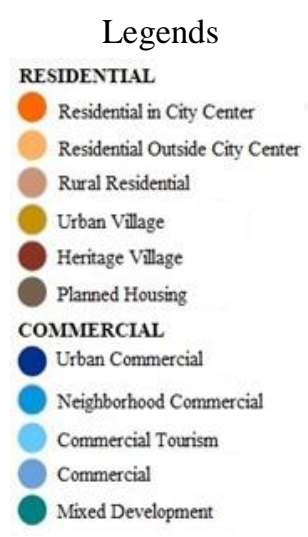

Fig. 1 - (a) Location of Batu Rakit Primary School on Google Maps with land zoning (b) Location of Paya Bunga Primary School on Google Maps with land zoning (Source:Google Map (2019) [10]) (Source: Kuala Nerus Local Plan and Kuala Terengganu Local Plan (2018) [9])

\subsection{Data Collection}

This study was started with monitoring the environmental noise in the study areas. The noise was measured at 30 different sampling points as depicted in Fig. 2. Noise data collection campaign were performed on three school and non-school days in determining the noise level variation. The sampling was conducted 3 times in a day which is at morning peak from 0700 hours until 0900 hours, afternoon peak from 1200 hours until 1400 hours and evening peak from 1700 hours until 1900 hours and the time interval for the sampling for each of the 30 sampling points is 4 minutes. 


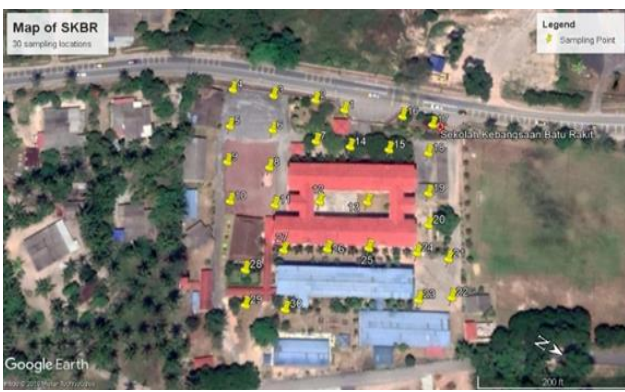

(a)

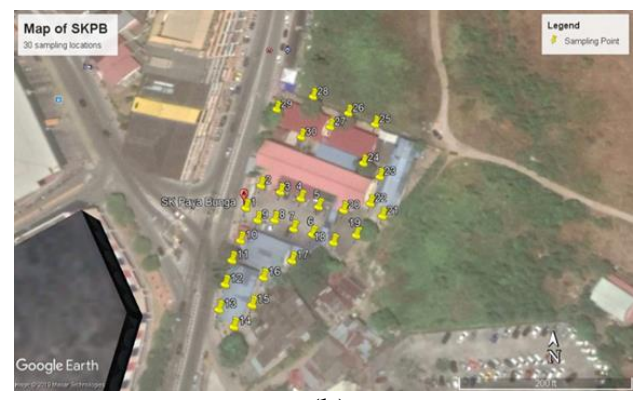

(b)

Fig. 2 - (a) Sampling Points at Batu Rakit Primary School (b) Sampling Points at Paya Bunga Primary School (Source: Google Map (2019) [10])

Three parameters were collected including the noise level, wind speed, and the coordinates (latitude, longitude) at study areas. Extech Sound Level Meter (SLM) Model HD600 that complies with IEC 61672 Class 1 Standard (Fig. $3(\mathrm{a})$ ) is used for noise level measurement. SLM is a handheld device equipped with a microphone. The noise level that was displayed on the screen of SLM was in the unit of decibel (dB). Kanomax Climomaster 6501 multi-function hot wire anemometer (Fig. 3(b)) is used for measuring the wind speed and it must be less than $5 \mathrm{~m} / \mathrm{s}$. Coordinates of sampling points that were taken at every point during the sampling were using the Global Positioning System (GPS) (Fig. 3(c)). This instrument was utilized to quantify the longitude and latitude of the sampling points at study areas.

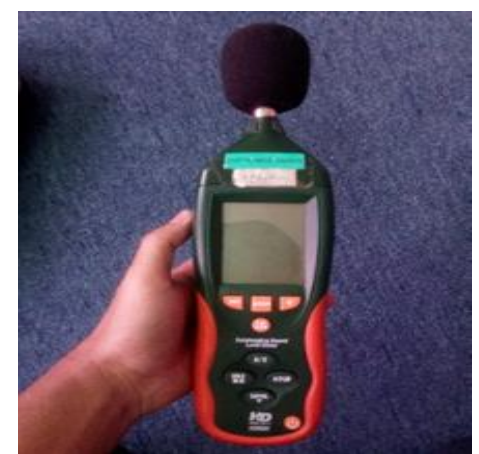

(a)

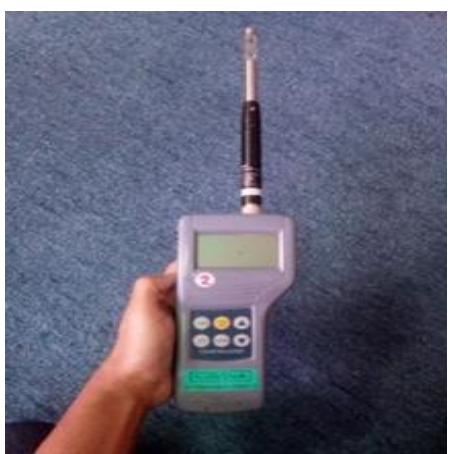

(b)

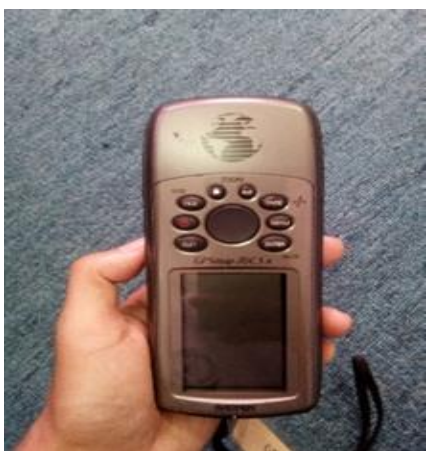

(c)

Fig. 3 - (a) Extech Sound Level Meter (SLM) Model HD600 that comply with IEC 61672 Class 1 Standard; (b) Kanomax Climomaster 6501 multi-function hot wire anemometer; (c) Global Positioning System (GPS) (Source: Air Quality and Sound Laboratory (2019) [7])

\subsection{Data Analysis}

The maximum noise level $\left(\mathrm{L}_{\max }\right)$ and the minimum noise level $\left(\mathrm{L}_{\min }\right)$ were established by analyzing the data using Microsoft Office Excel 2016. The equivalent noise level $\left(\mathrm{L}_{\mathrm{Aeq}}\right)$ was calculated by using Equation 1, which expressed in unit dBA.

$$
L_{\text {Aeq }}=10 \log \sum_{i=t}^{i=n}(10)^{L i / 10}\left(t_{i}\right)
$$

where $n$ is the total number of samples taken, $L i$ is the noise level in dBA of the $i$ th sample, and $t_{i}$ is the fraction of the total sample time.

The noise level is considered as complies The Planning and Guideline for Environmental Noise Limit and Control (2019) [11] if $\mathrm{L}_{\text {Aeq }}$ value does not exceed the existing guideline for maximum $\mathrm{L}_{\text {Aeq }}$ by Receiving Land Use for Planning and New Development. $\mathrm{L}_{\max }$ is the highest sound level and $\mathrm{L}_{\min }$ is the lowest sound level collected during the study period [6]. The noise level dataset is arranged in ascending order. The evaluation of $\mathrm{L}_{10}$ and $\mathrm{L}_{90}$ were conducted in Microsoft Office Excel 2016 by using [= PERCENTILE (array, k)], and inserting k=0.9 for evaluating the $\mathrm{L}_{10}$ and $\mathrm{k}=0.1$ for $\mathrm{L}_{90}$. The $\mathrm{L}_{10}$ is the noise level in $\mathrm{dBA}$, exceeded only by $10 \%$ of the time or Peak Sound Level and also known as traffic noise. Meanwhile, $\mathrm{L}_{90}$ is the noise level in dBA, exceeded $90 \%$ of the time or otherwise known as residual or background noise level [6]. Then, Analysis of variance (ANOVA) test was used to establish a significant difference in noise level at each study area during the school day and non-school day. Noise maps were constructed using SketchUp® 2018 and the Surfer ${ }^{\circledR}$ version 11 software. 


\section{Results and Discussion}

\subsection{The trend of Environmental Noise}

The noise level trend had depicted in Fig. 4(a) (school day during peak time) and Fig. 4(b) (comparison during the school day and non-school day). The noise level during the school day for S1 and S2 during morning peak is 50.8 dBA and 53.3 dBA, respectively. During morning peak hours, students and teachers arrived at the school to start their activities, such as morning assembly and teaching sessions. The noise level was slightly increasing during the afternoon peak for both study areas with 52.6 dBA for S1 and 55.3 dBA for S2. Most primary schools in Malaysia end their school session around the afternoon peak. The students and teachers leave the school area that may lead to the accumulation of motor vehicles in the school area as the parents come to fetch their children at school. Therefore, the parents stop and park the motor vehicles along the shoulders of the road, near the school area. Thus, the accumulation of motor vehicles at the school area will contribute to the higher noise level that will expose to the receptors. The parents fetch their children at the same period hour from the school caused considerable traffic congestion [12]. This situation demonstrates how an increase in noise level is linked to certain driving behaviors' including honking, speeding up, and creating other noise sources [13]. Then, the noise level slightly decreased during the evening peak compared to the afternoon peak for both study areas with $51.9 \mathrm{dBA}$ for S1 and $53.1 \mathrm{dBA}$ for S2. During the evening peak, most of the primary schools in Malaysia vacated as the school session ended. The noise level exposed to receptors throughout this period is lower than the noise level exposed to receptors during the afternoon peak. S1 has a lower noise level during the school day than on a non-school day, while S2 has a greater noise level during the school day than on a non-school day, as shown in Fig. 4(b). S1 recorded 39.7 dBA to 58 dBA during the school day and $39.4 \mathrm{dBA}$ to $59 \mathrm{dBA}$ during the non-school day, while S2 recorded $33.6 \mathrm{dBA}$ to $60 \mathrm{dBA}$ during the school day and $40.5 \mathrm{dBA}$ to $55.8 \mathrm{dBA}$ during the non-school day, as many motor vehicles passed by the main road of this school, which was sometimes dominated by heavy trucks such as lorries and trailers, which influenced the noise [6].

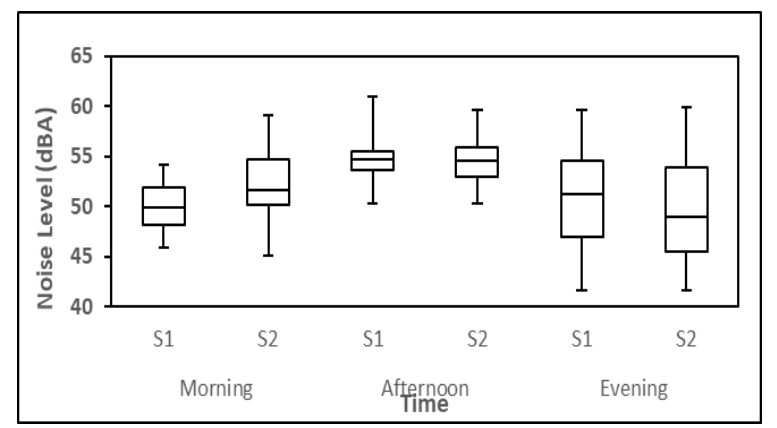

(a)

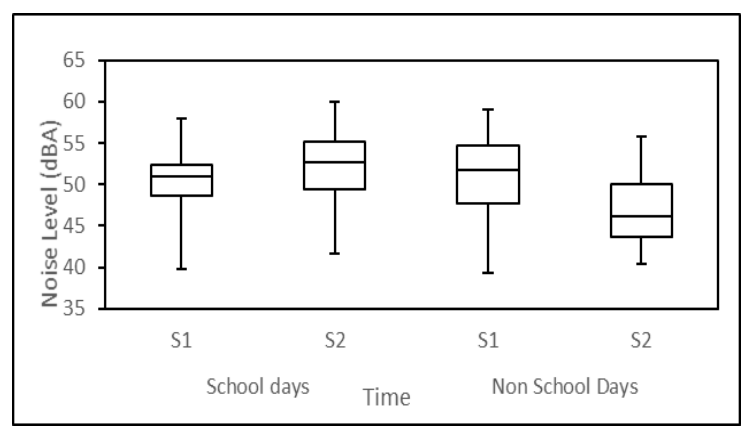

(b)

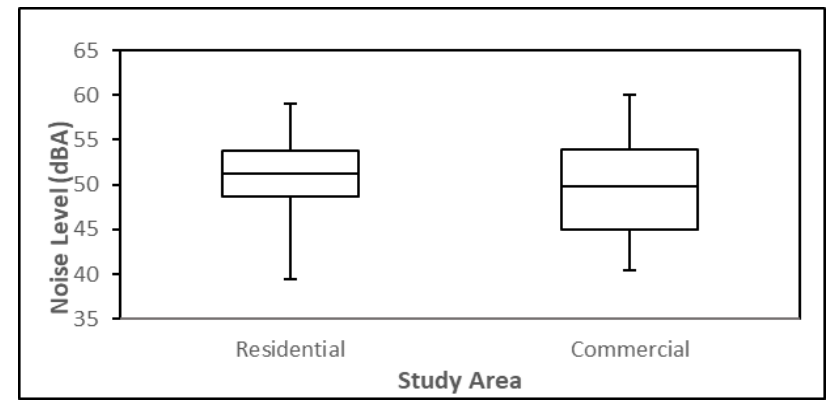

(c)

Fig. 4 - The trend of noise level (a) during school days at different peak time; (b) with comparing between school days and non-school days; (c) noise level at study areas during the school day and non-school day

The noise level in a residential area is kind of higher than the noise level in a commercial area, as shown in Fig. 4(c), which is $60.3 \mathrm{dBA}$ for residential and $60 \mathrm{dBA}$ for commercial. Statistically, there exists a significantly different $(\mathrm{p}<0.05)$ of noise level at the two study areas. This is due to traffic density as the schools are located near the main roadside and the noise that produce from surrounding activities such as teaching and learning sessions and students playing nearby the sampling site. The school located in the commercial area (S2) has a higher value of Lmax which is $60 \mathrm{dBA}$ instead of the school located at a residential area (S1) (59 dBA) for both school and non-school days. The high 
noise level might be due to the sampling areas are the near-religious center. Previously, Emenike \& Sampson [15] proved that the religious center used loudspeakers can trigger a high noise level.

Fig. 5(a) and Fig.5(b) separately show the compliance of the equivalent noise level ( $\mathrm{L}_{\text {Aeq }}$ ) for both study areas during school and non-school days. Standard noise limits $\left(\mathrm{L}_{\mathrm{Aeq}}\right)$ authorized by the Malaysian Department of Environment (DOE) for daytime (0700 hours to 2200 hours) at the school zone is $50 \mathrm{dBA}$ since the school is arranged as one of the noise-sensitive areas. During the study, both study areas have exceeded the limit that stated in The Planning Guidelines for Environmental Noise Limit and Control (2019) that provided by DOE, whereby the equivalent noise level was higher at the residential area $(60.3 \mathrm{dBA})$ compared to the commercial area (60 dBA) due to amount of traffic in each study area during sampling.

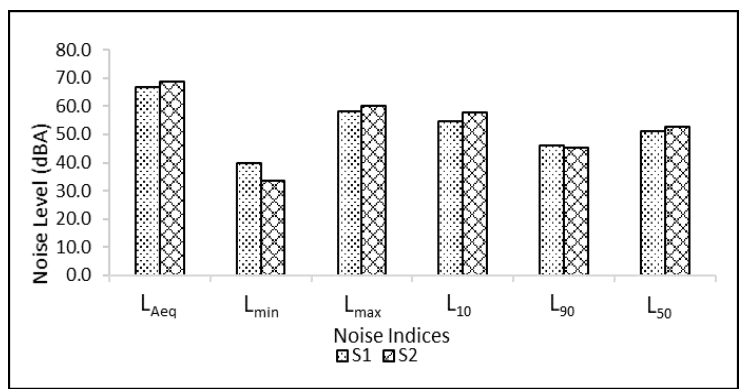

(a)

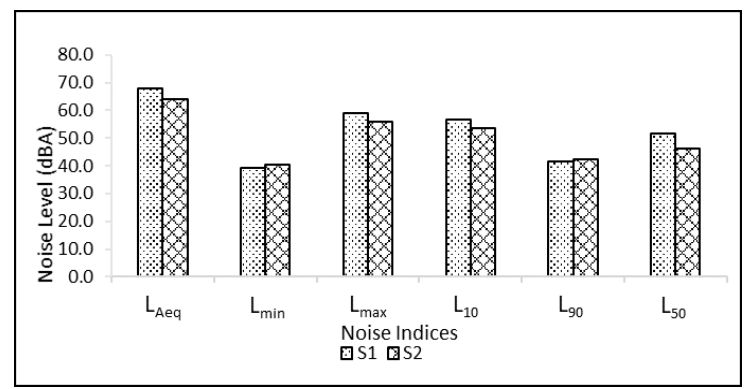

(b)

Fig. 5 - Noise indices at study areas (a) during school days and (b) non-school days

The noise level at the residential area was higher during non-school days rather than school days due to high traffic density during the weekend. Families fulfil their leisure time during the weekend, using cars instead of motorcycles, triggering high traffic density. Yellow strips in the residential area increase noise level as people speed up their motor vehicles instead of slows down. High traffic density of cars compare with motorcycle emits high noise as the cars' engines are much larger [6]. Traffic noise $\left(\mathrm{L}_{10}\right)$ showed that the level is $54.7 \mathrm{dBA}$ for S1 and $57.7 \mathrm{dBA}$ for S2 on a school day while $56.8 \mathrm{dBA}$ for S1 and 53.5 dBA for S2 on a non-school day. Meanwhile, background or residual noise $\left(\mathrm{L}_{90}\right)$ at both study areas showed that the level is the highest at S1 during the school day and S2 during the non-school day with $46 \mathrm{dBA}$ and $42.4 \mathrm{dBA}$, respectively. Besides, the noise level exceeded for $50 \%$ of the time $\left(\mathrm{L}_{50}\right)$ is highest at $\mathrm{S} 2$ during the school day and S1 during the non-school day with $52.7 \mathrm{dBA}$ and $51.8 \mathrm{dBA}$, respectively.

\subsection{Spatial Mapping}

The noise maps of the study area were drawn; critical points are shown with the red colour while the lowest noise levels were shown with purple colour. The benefits of constructing the noise map according to a previous study by Manojkumar et al. [16], alarming noise levels were found near study areas on noise maps, prompting recommendations for immediate noise mitigation measures such as barriers or alternative traffic routes. Alam et al. [17] stated that the noise map is a graphical representation of noise levels that is commonly used as a guidance in urban noise management. Noise mapping can also be used to estimate a location's environmental noise exposure. As a result, noise maps should be utilised in conjunction with strong action recommendations as a strategic tool for limiting and managing environmental noise [18].

Fig. 6(a)-(c) shows noise map during different peak hours on school day; (a) 0700hrs until 0900hrs (morning), $1200 \mathrm{hrs}-1400 \mathrm{hrs}$ (afternoon) and $1700 \mathrm{hrs}-1900 \mathrm{hrs}$ (evening). The red zone in Fig. 6(a) mainly in the areas of entrance and roadside of the study area, with the range from 51.1 dBA to 54.3 dBA. According to a previous study by [18], the road that connects the college's entrances has excessive noise levels, making it the principal source of noise within the campus area. The highest noise level in Fig. 6(b) was $58 \mathrm{dBA}$ which is $3.7 \mathrm{dBA}$ higher than Fig. 6(a). Increased traffic volume during the afternoon was due to the end of the school session. The maximum noise level in Fig. 6(c) during this period is $51 \mathrm{dBA}$ to $57.7 \mathrm{dBA}$.

Fig. 6(d)-(f) shows a noise map during different peak hours on a non-school day. The maximum noise level in Fig. 6(d) is higher than the morning peak of the school day (Fig. 6(a)) of $56.5 \mathrm{dBA}$ and $54.2 \mathrm{dBA}$, respectively. Noise levels in many parts range from 52 to $58 \mathrm{dBA}$ (Fig. 6(e)). The highest noise level recorded was $57.6 \mathrm{dBA}$ at 1204 hrs because the area is nearby the roadside. The maximum noise exposure during in Fig. 6(f) is 50.4 dBA to 59 dBA.

Fig. 7(a)-(c) shows noise map during different peak hours on school day; (a) 0700hrs until 0900hrs (morning), $1200 \mathrm{hrs}-1400 \mathrm{hrs}$ (afternoon) and 1700hrs - 1900hrs (evening). In Fig.7(a), the noise level at the main roadside demonstrates the high level of noise induced by increased road congestion. The number of vehicles was expanding during the morning time and became peaked at noon, while it is decreasing during the evening [19]. At 0748 hours, the maximum level of noise recorded was $59.2 \mathrm{dBA}$. The highest level of noise recorded in Fig. 7(b) was $59.6 \mathrm{dBA}$ at 1320 hrs caused by the sound of the adhan from the mosque located nearby to the school. The surrounding activities such as 
students playing nearby the sampling site also contribute to the noise pollution during the period. Noise levels in many parts range from 42 to $52 \mathrm{dBA}$ (Fig. 7(c)). The location closest to the roadside had the highest level of noise at $60 \mathrm{dBA}$.

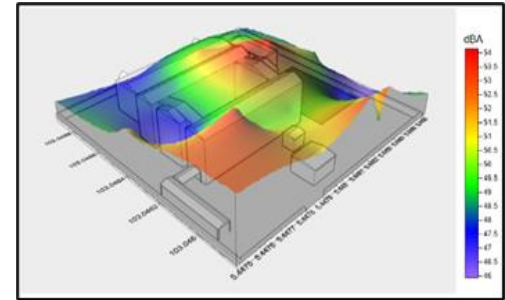

(a)

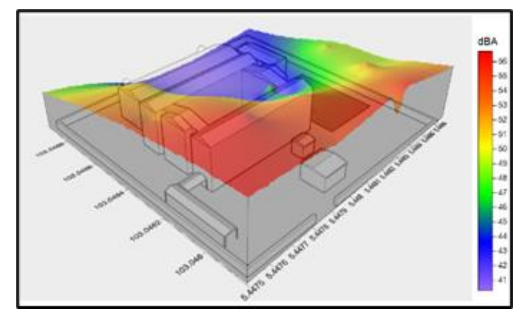

(c)

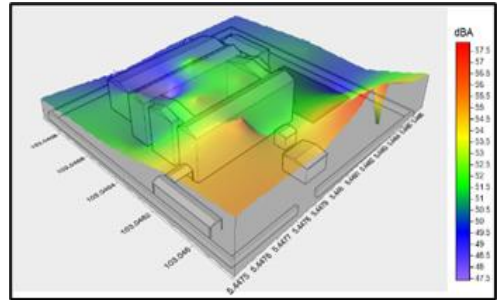

(b)

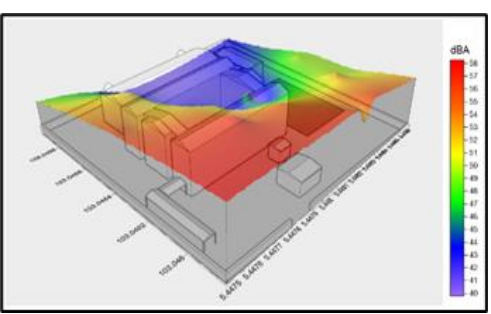

(e)

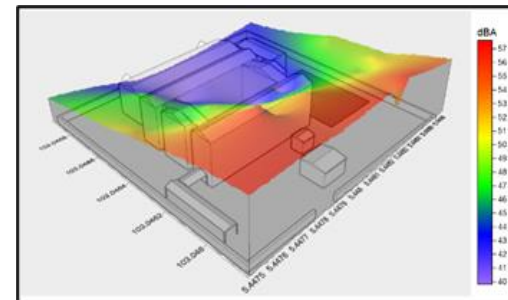

(c)

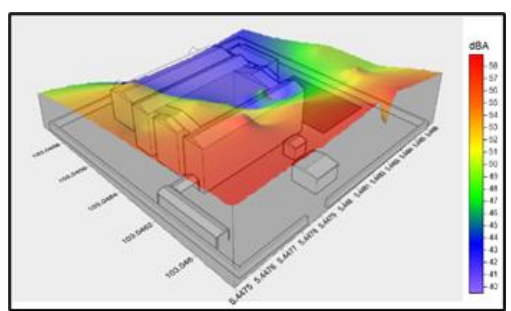

(f)

Fig. 6 - Noise map of S1 during school day (a) morning; (b) afternoon; (c) evening and non-school day (d) morning; (e) afternoon; (f) evening

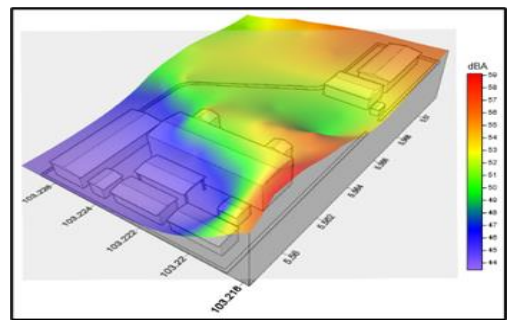

(a)

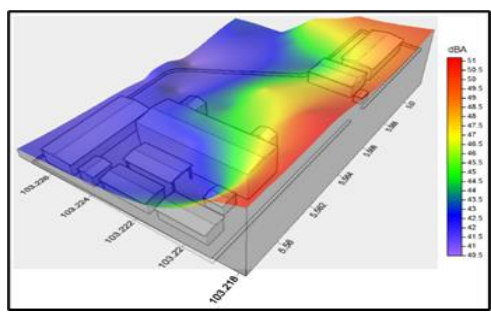

(d)

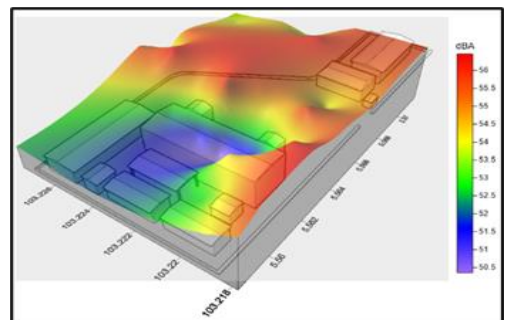

(b)

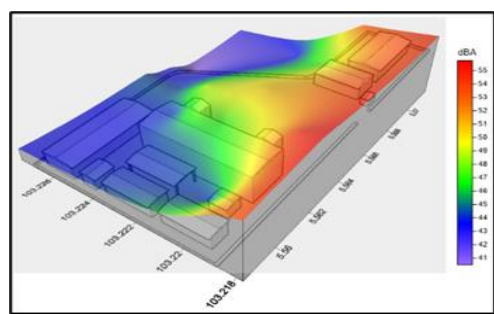

(e)

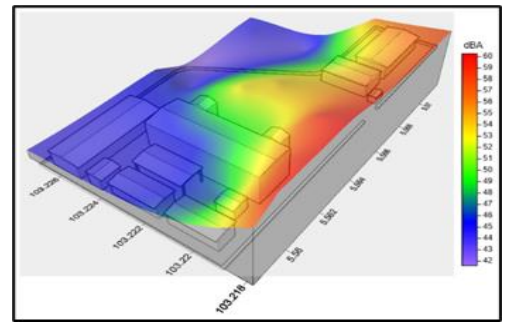

(c)

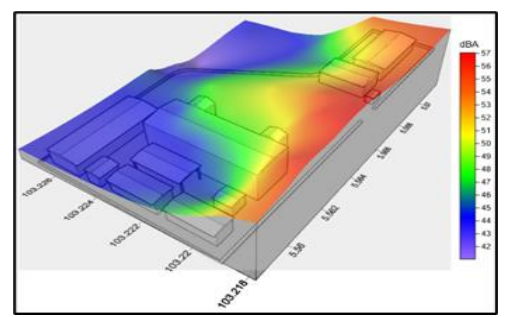

(f)

Fig. 7 - Noise map of S2 during school day (a)morning; (b) afternoon; (c) evening and non-school day (d) morning; (e) afternoon; (f) evening

\section{Conclusion}

The trend of environmental noise at both study areas with different land use of the residential and commercial was achieved based on results through the boxplot for school and non-school days. Analysis of Variance (ANOVA) shows that there exists a significantly different $(\mathrm{p}<0.05)$ of noise level at two study areas, with the highest noise level obtained at residential followed by commercial areas. Spatial mappings show that the red zone indicated at the entrances to the schools and area near the roadside, which due to increasing traffic volume. The purple zones were indicated the noise level in the place that far away from the roadside.

\section{Acknowledgement}

This study is funded by the Fundamental Research Grant Scheme for Research Acculturation of Early Career Researchers by the Malaysian Ministry of Education (RACER/1/2019/TK10/UMT//1). We also would like to thank the Air Quality and Noise Laboratory, UMT for instruments acquisition. 


\section{References}

[1] Haron Z., Han L. M., Darus N., Lee Y. L., Jahya Z., Hamid M. F., Yahya K. \& Shek P. N. (2015). Preliminary study of environmental noise in public university. Jurnal Teknologi, 77(16), 145-151

[2] Kumar D. (2018). Abatement of Noise Pollution in Sustainable Management of Coal Preparation. Woodhead Publishing, pp. 279-291

[3] Shekhar S., Jiang Z., Ali R. Y., Eftelioglu E., Tang X., Gunturi V. M. V. \& Zhou X. (2015). Spatiotemporal data mining: A computational perspective. ISPRS International Journal of Geo-Information, 4, 2306-2338

[4] Mutalib H., Mashros N., Aminudin E., Zakaria R., Haron Z., Talib H. \& Hamid R (2018). Disturbance of traffic noise: evaluation on the effects and management on road corridors. Earth and Environmental Science, 143, 012049

[5] Silva L. T., Oliveira I. S. \& Silva J. F. (2016). The impact of urban noise on primary schools perceptive evaluation and objective assessment. Applied Acoustics, 106, 2-9

[6] Ismail M., Abdullah S. \& Fong S. Y. (2015). Study on environmental noise pollution at three different primary schools in Kuala Terengganu, Terengganu State. Journal of Sustainability Science and Management, 10(2), 103111

[7] Abdullah S., Akhtari M. I., Ismail M., Ahmed A. N., Mansor W. N. W. \& Zulkifli M. F. R. (2019). Spatiotemporal analysis of environmental noise in institutional area. International Journal of Recent Technology and Engineering, 8(2), 4037-4042

[8] Department of Urban and Regional Planning (2018). Draf Rancangan Tempatan Daerah Kuala Nerus 2035. Malaysia

[9] Department of Urban and Regional Planning (2018). Draf Rancangan Tempatan Daerah Kuala Terengganu 2035. Malaysia

[10] Google (January 12, 2019). Google Map of Kuala Terengganu. https://www.google.com.my/maps/ place/Kuala+Terengganu,+Terengganu/@5.4838498,102.7477846,10z/data=!3m1!4b1!4m5!3m4!1s0x31b7099e9 76e862f:0x1bc0ee85cb232492!8m2!3d5.329624!4d103.1370142

[11] Department of Environment (2019). Planning Guidelines for Environmental Noise Limits and Control. Putrajaya.

[12] Ghazali W. N. W., Zulkifli C. N. A. \& Ponrahono Z. (2020). The effect of traffic congestion on quality of community life. European Proceedings of Multidisciplinary Sciences, https://doi.org/10.15405/epms.2019.12.77

[13] Sulaiman F. S., Darus N., Mashros N., Haron Z. \& Yahya K. (2018). Traffic noise assessment at residential areas in Skudai Johor. E3S Web of Conferences, 34, 11-18

[14] Patil C. R., Kulkarn P. P., Sarode N. N. \& Shinde K. U. (2017). Gearbox noise and vibration prediction and control. International Research Journal of Engineering and Technology, 4(11), 873-877

[15] Emenike G. C. \& Sampson A. P. (2017). Noise levels and quality of livelihoods in residential neighbourhoods of Port Harcourt Metropolis Nigeria. European Journal of Earth and Environment, 4(1), 19-28

[16] Manojkumar N., Basha K. \& Srimuruganandam B. (2019). Assessment prediction and mapping of noise levels in Vellore City India. Noise Mapp, 6(1), 38-51

[17] Alam M. S., Corcoran L., King E. A., McNabola A. \& Pilla F. (2017). Modelling of intra-urban variability of prevailing ambient noise at different temporal resolution. Noise Mapp, 4(1), 20-44

[18] King E. A. \& Murphy E. (2016). Environmental noise 'forgotten' or 'ignored' pollutant? Applied Acoustics, 112(1), 211-215

[19] Abdullah S., Helmi A. A., Annuar A. Z. \& Mansor W. N. W. (2019). Sensitivity and suitability of environmental noise monitoring device: A preliminary study. International Journal of Mechanical Engineering and Technology, $10(2), 858-864$ 